\title{
Design and Implementation of Database Management for Presidency of Diyala University
}

\author{
Warqaa Shaher AlAzawee, Ahmed M. Jasim, Sabah Anwer Abdulkareem \\ Department of Computer Engineering - College of Engineering - University of Diyala \\ Corresponding Auther Email: warqaa_shaher@yahoo.com, ahmed.1985m@yahoo.com,sbh_anwar@yahoo.com
}

\begin{abstract}
In our life, computer has entered in all fields and its impact appeared in solving many of problems. One of those problems is the ability to store and deal with a huge amount of data. Also, the consequent method of indexing, retrieving and preserving that data requires cost and effort we need for a long time. In this paper, the authors designed and implemented a new method of database for the Office of Security Permits at University of Diyala to resolve the routine process and change the traditional work into an advanced digital work. This database has designed based on a software application with interface programed in $\mathrm{C \#}$ and using Microsoft Access. The results show that this database management system has reflected remarkable achievement in administrational work at Office of Security Permits because it makes everything easy to deal with such as storing, adding, deleting data and printing the final reports.
\end{abstract}

Keywords- Database Management System, University of Diyala; Security Permits Office, C\# program language, Microsoft Access.

Paper History:(Received:19-9-2019 ;Accepted:6-11-2019)

\section{Introduction}

Data base is one of the latest contemporary methods in information processing to ensure providing an easy, quick and organized access methodology [1]. Database can be classified in to three categories: Hierarchical Databases, Networked Databases and Associated Databases. These categories show how the relationship between the tables and records have been structured. A database project can be small and large depend on the size of data [2]. Different programs have been developed to build tables for database such as, Microsoft Access, paradox, FoxPro DBASEIII, EX- Oracle and SQL (Structured Query Language) [2]. Moreover, there are set of programming languages that help determine logical organization of data and how to access these databases and use their information. In this work, the tools that had used are Microsoft Access and visual C\# because they are widely spread, very simple and easy to learn [3].

\section{Microsoft Access}

Microsoft Access is a database management software. It is developed by Microsoft. This program comes as a part of Microsoft Office, and it has a graphical interface. Microsoft has released several versions of this program which are: Office 97, 2000, 2003, 2007, 2010, 2013, 2016 and the latest version is Office 2019 [4]. Microsoft Access help us store information for reference, reporting, analysis large amounts of information, and manage related data more efficiently than other spreadsheet applications and Microsoft Excel. The authors recommend MS Access over other databases in this work because of the benefits and advantages of using Microsoft Access [5]. Microsoft Access is used to create quick, easy databases and provide a user-friendly interface and Convenient storage capacity. In addition, it is widely popular, Multi-user support and it produces flexible and adaptable databases systems. As a result, Microsoft Access is a very effective and reliable databases management tool [5].

\section{Visual C\# language}

It is pronounced $\mathrm{C}$ sharp. $\mathrm{C \#}$ is a new programing language that was released in 2002 [6]. It is designed for building a wide range of applications that run on the .NET Framework, and it is introduced as Visual C\# in the Visual Studio [7]. Visual C\# includes support for many things such as project templates, designers, code wizards, property pages and an object model. Its library is the NET Framework. Also, there are many features and reasons that make this language a widely used professional language [8]. Its Object oriented, Easy to learn, Structured language, modern and general purposes programing language. Moreover, the important features of $\mathrm{C \#}$ are Boolean Conditions, Automatic Garbage Collection, standard Library, indexers and integration with windows. All these things make this language fulfils our needs for this project [9].

\section{Methodology \& EXPERIMENTAL Results}

The authors used MS Access and Visual C\# language as the focal tools in this method which is composed of several steps shown in Figure 1. 


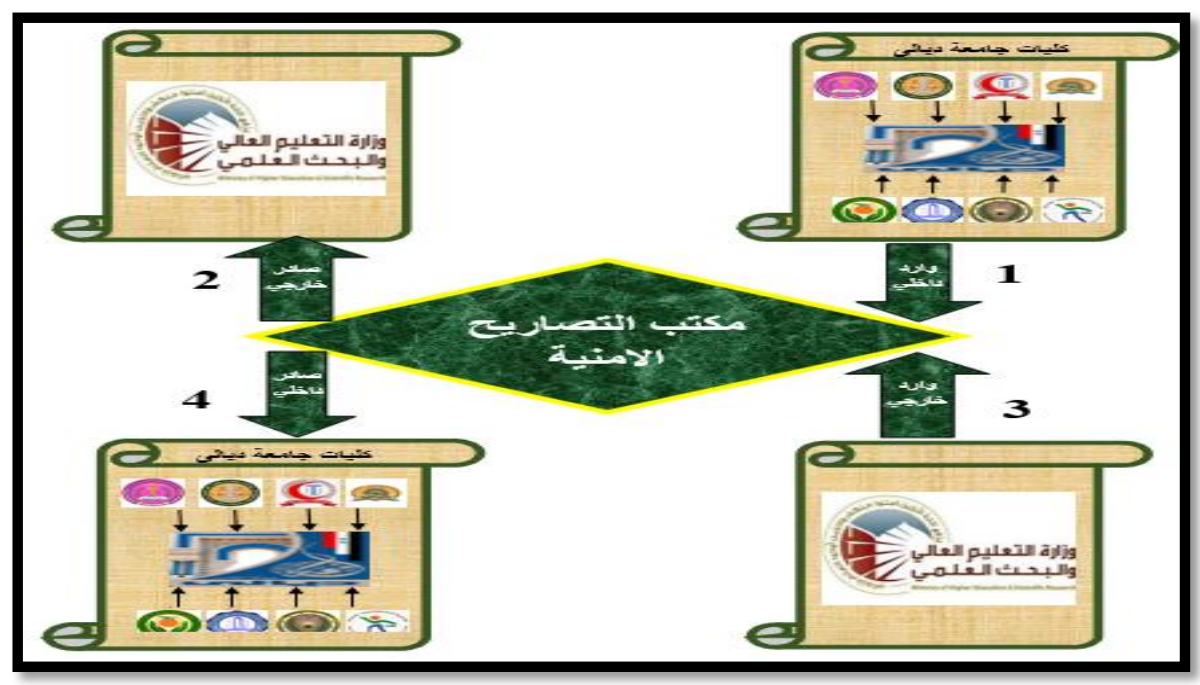

Figure 1: illustrates the sequence of work steps in the Security Permits office

According to the requirements of the presidency of the University of Diyala and the sequence of work steps in the Security Permits Office. This program consists of several windows that will be explained in the following section.
Also, we designed Security Permits program icon that is shown in figure2

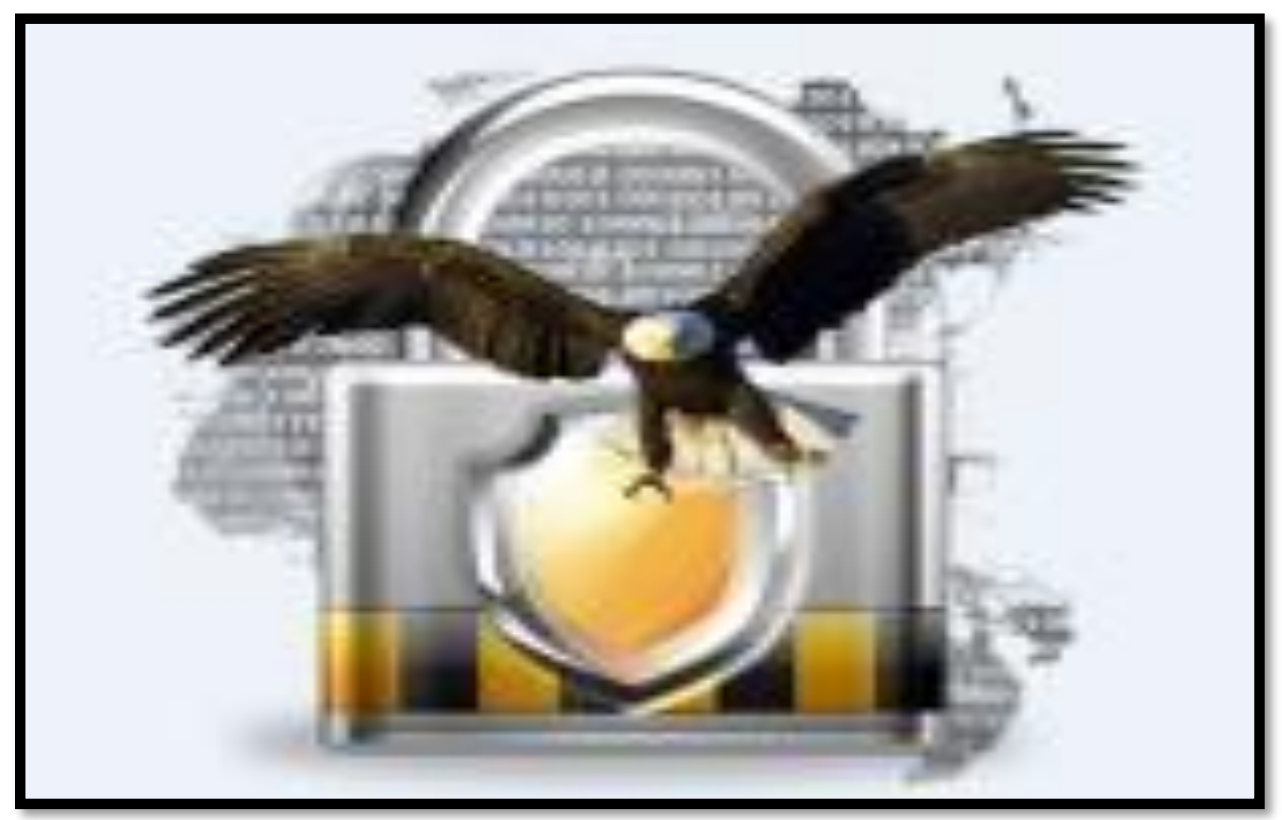

Figure 2: Security Permits Program Icon

\section{Step 1: Interface Entry}

The interface entry window is the first window in this project. It is designed in order to make our databases system more secure, so no one can use the system without authorization. Also, this window is controlled by one admin who has ability to add more users. This window consists of a textbox to enter a user name, a textbox to enter the password and three other buttons namely as Add new user, Entry and Exit. Figure 3 shows the interface Entry 


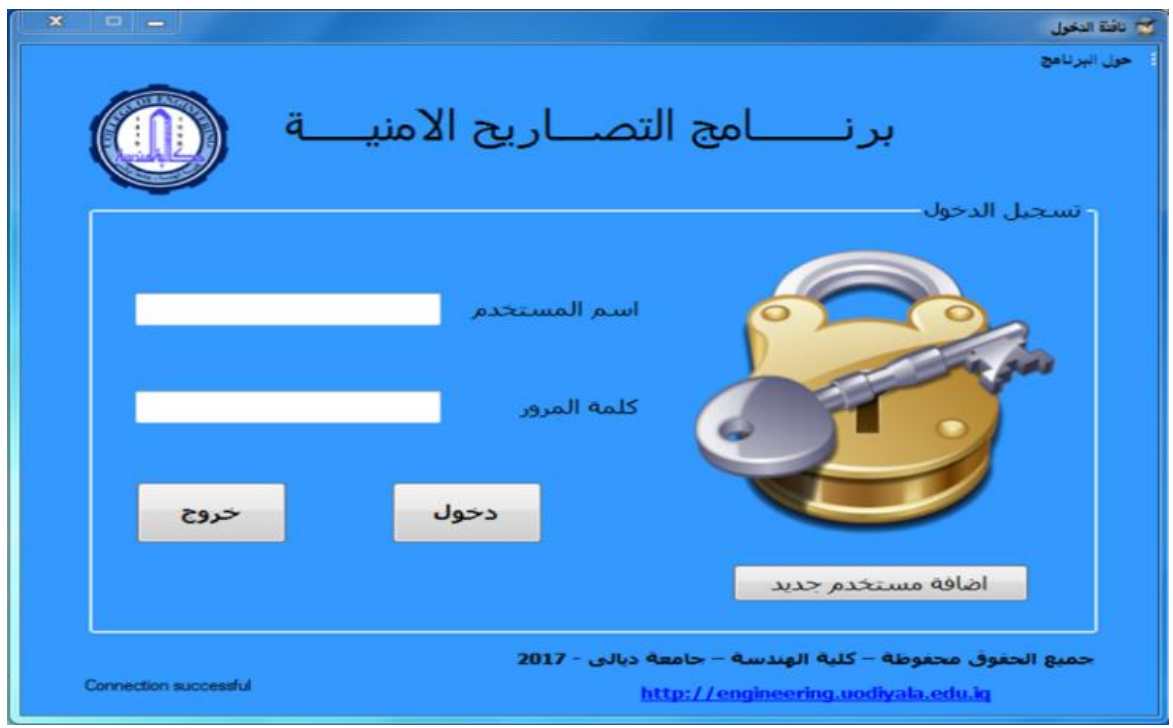

Figure 3: Interface Entry

This window provides ability to add new user by pressing on the button Add see figure (4). It is controlled by director to login and add a new user by adding his/her name and password, and then any user whose name was entered and password passed is authorized to use the program and enter the system and complete his/her work. The names and passwords of the administrator and all users are stored in a table in the Access program, if a name or password is entered that does not match what is in the Users table, a message will appear that the user name and password are incorrect.

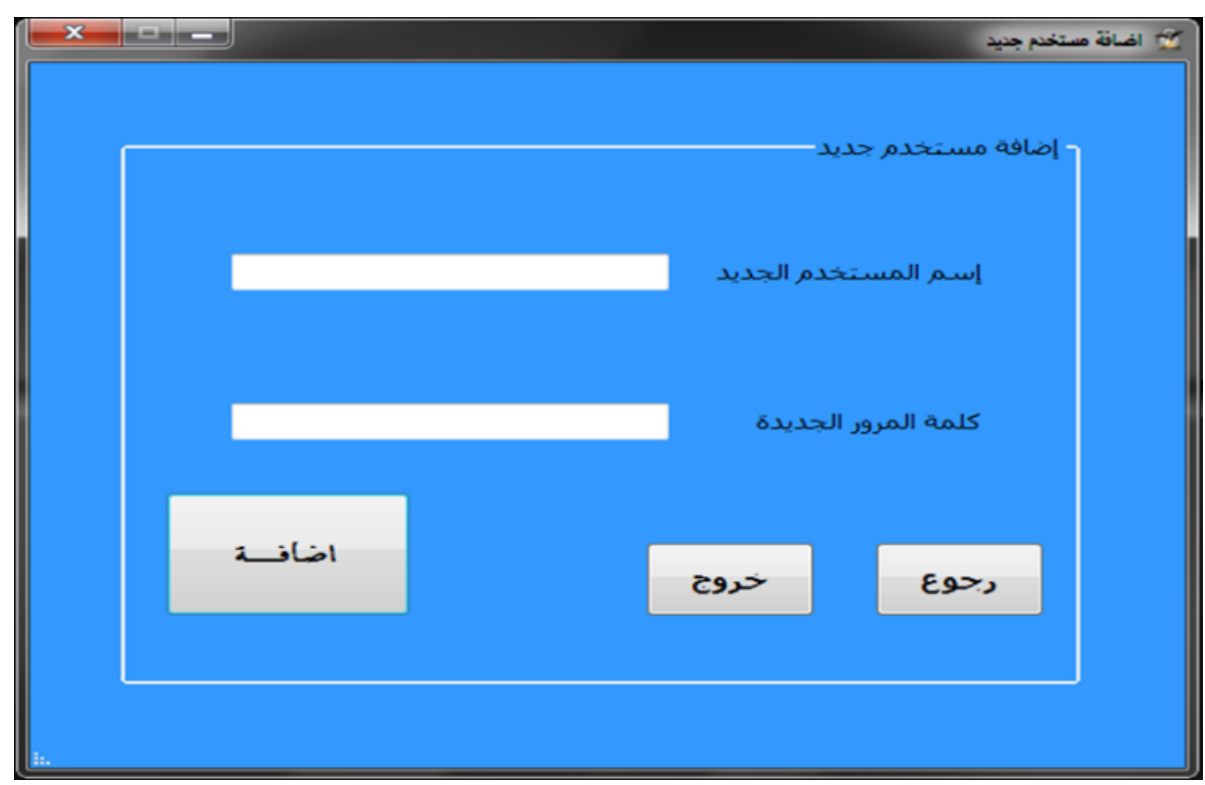

Figure 4: Add a New User

\section{Step 2: Interface for program details}

This window is designed to learn more about the program details see Figure 5: 


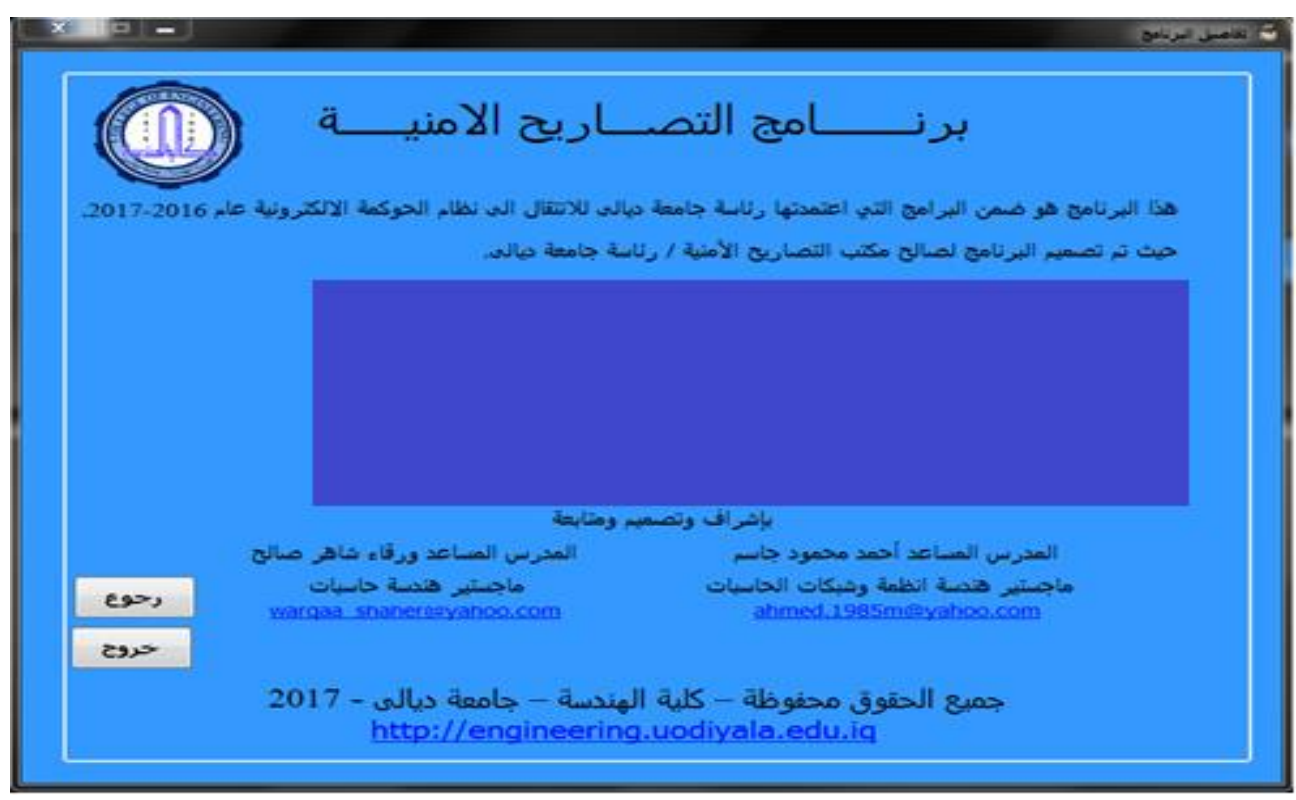

Figure 5: Program Details

Step 3: Interface for Main Menu

This window is essential window for in this designed program. It presents the entry for all windows in our databases system. It consists of six buttons which are:
Internal Incoming, External Incoming, Internal outcoming, External out-coming, Back and Exit. See Figure 6.

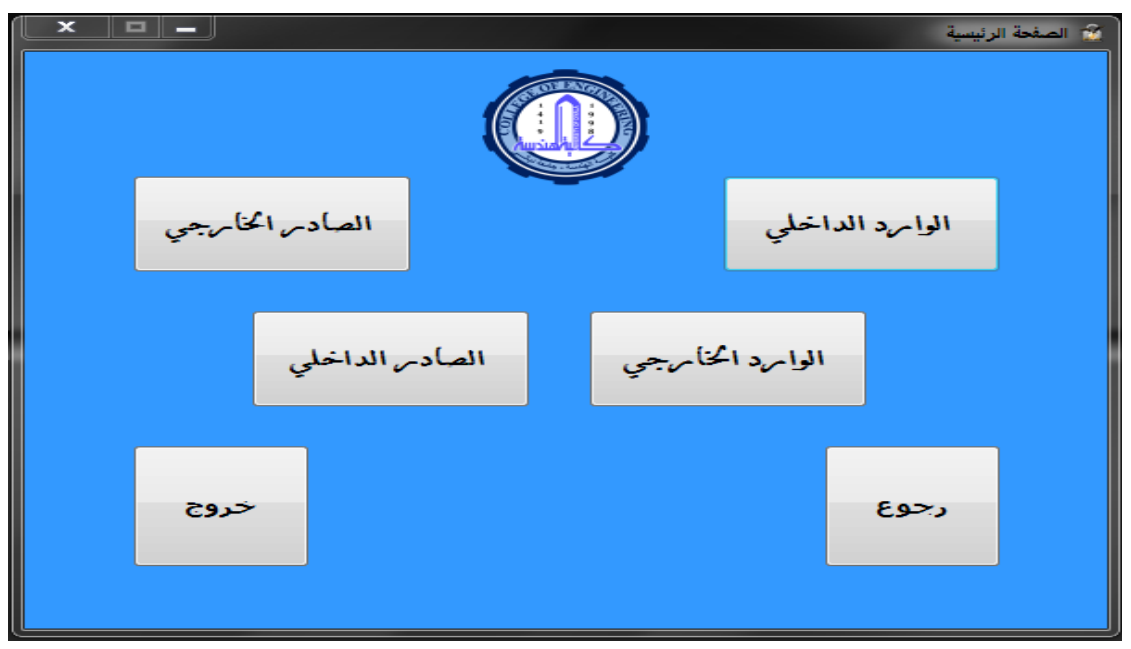

Figure 6: Interface for main Menu

Internal Incoming is used to file the incoming documents from colleges or departments of University of Diyala regarding the situation of security for any employee.
This window provides the buttons to add a new information, edit, view the record, back and exit from the window see figure 7 . 


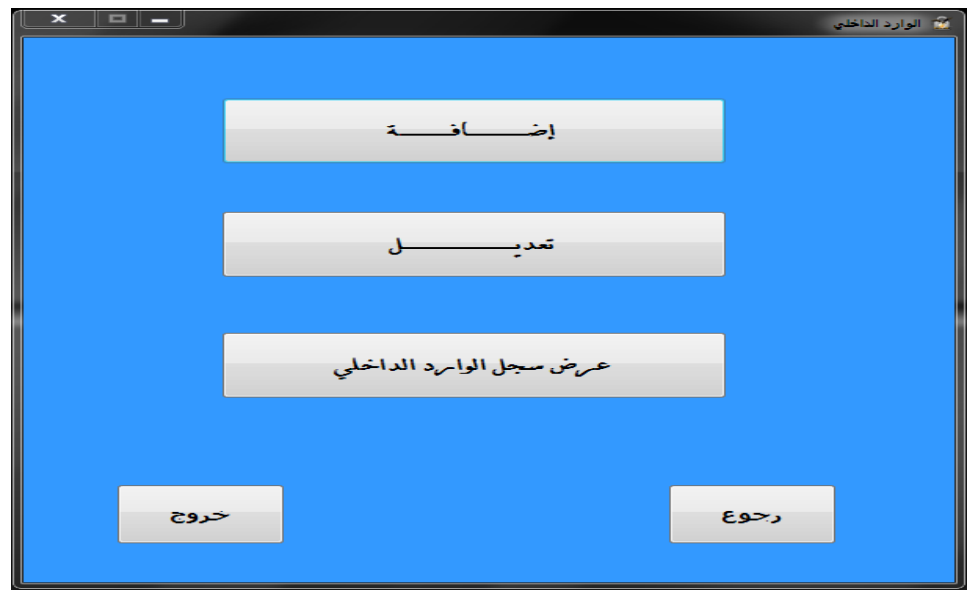

Figure 7: Internal Incoming window

For adding Internal incoming document, we designed a window for the purpose of archiving data, and stored it in a special internal incoming Table (Databases) see figure 8.

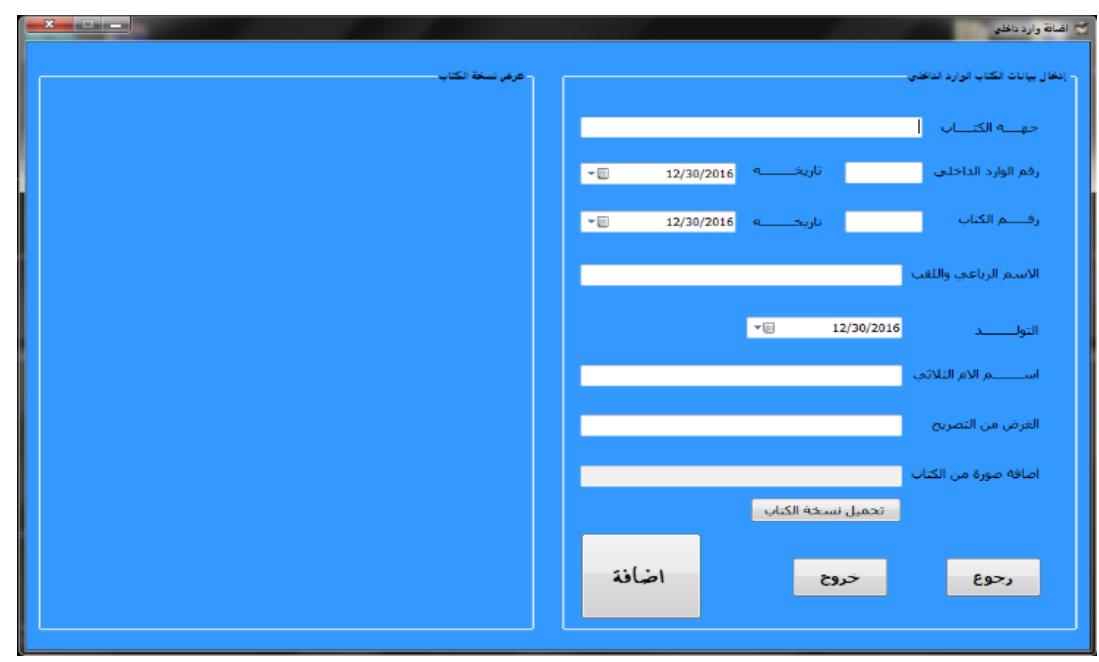

Figure 8: Adding Internal incoming

In case of error occurrence, we provided the possibility of errors corrected by adding a property of editing and deleting information see figure (9).

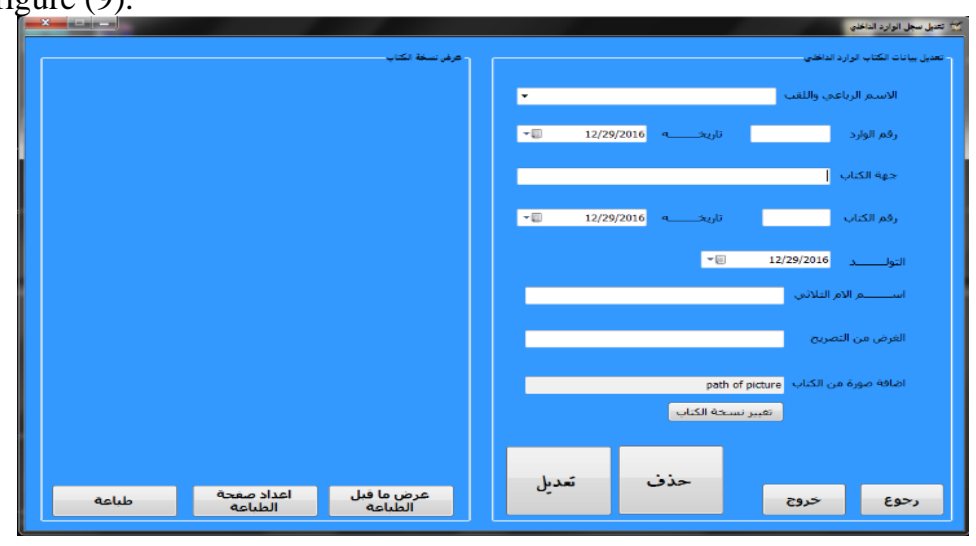

Figure 9: Editing Internal incoming

Also, we provided the ability to view the table of information. We can search any information by writing the first letter of the name or by writing the full name see figure (10). 


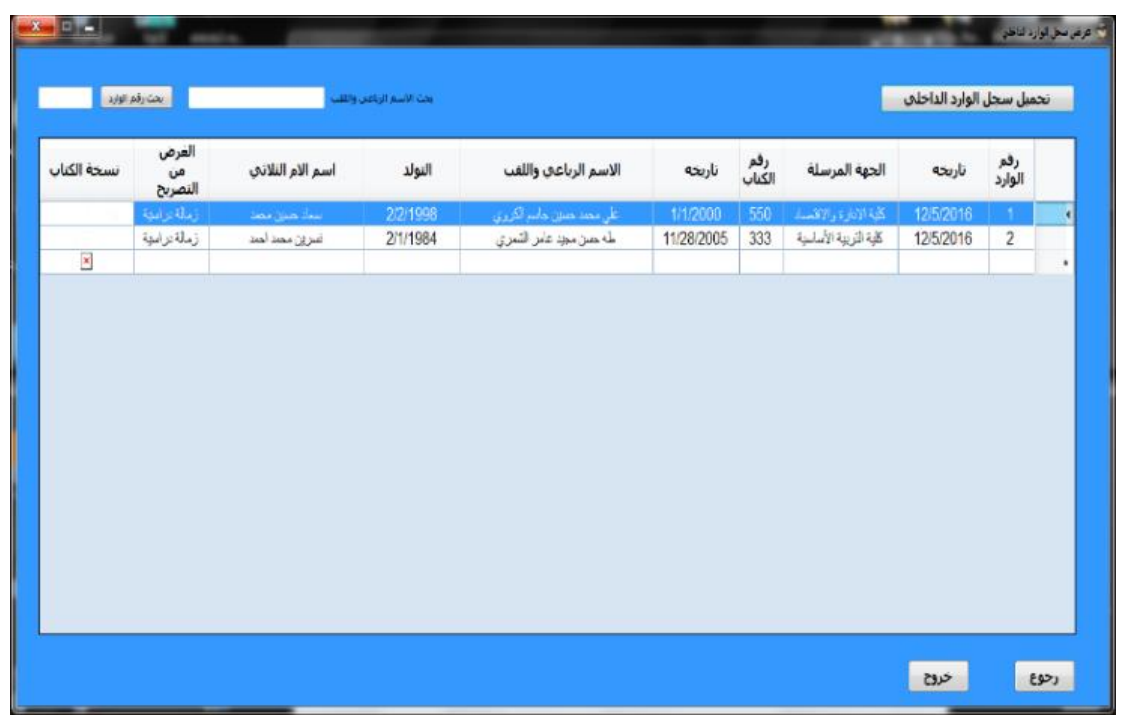

Figure 10: View Internal Incoming

External Outcoming is a document that should be sent by the Office of Security Permits to the Ministry of Higher Education to get the authorization security. To organize and archive the information on this document we designed a window that includes ability to Print document, Add, Edit and View of information in this issued document see Figure 11 .

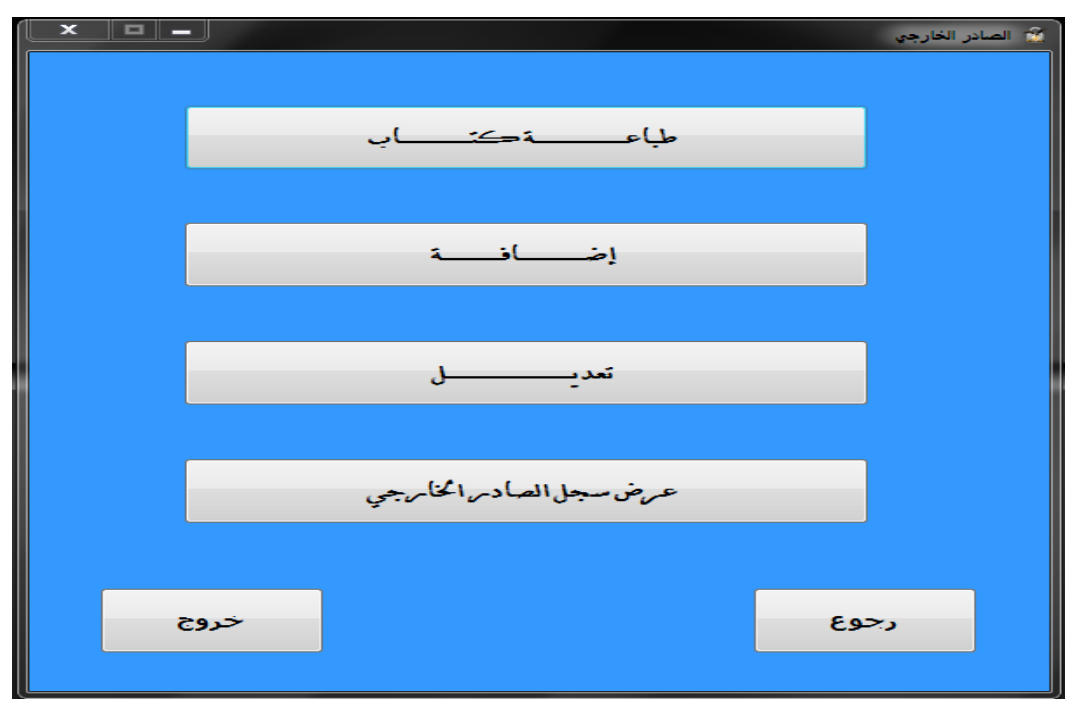

Figure 11: External outcoming window

To print a document, to be sent, we designed the print outcoming external window. The information is added from temporary data table that is created for just employees, we want to get authorization security for them by pressing on bottom add and modify see figure 12 . 


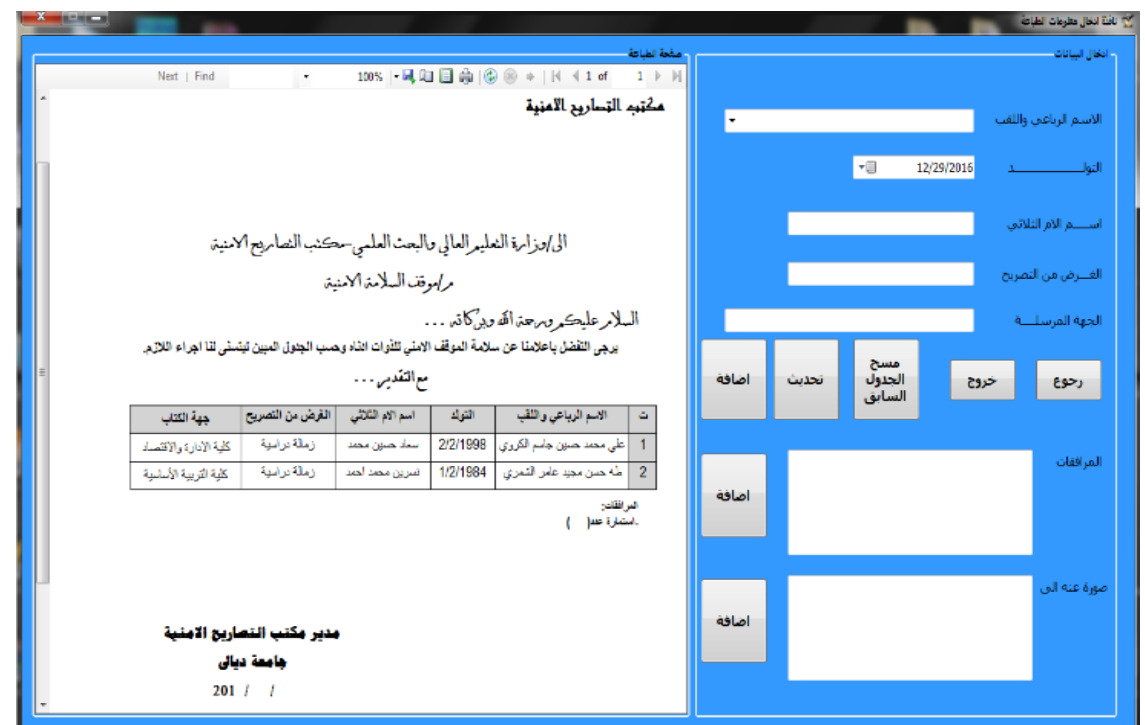

Figure 12: Print External Outcoming

Also, this external outcoming window has the ability to Add, Edit and View the information in the external outcoming document in the same way that we do in internal incoming document.

Now, External Incoming is the document that comes from the Ministry of Higher Education and Scientific
Research as a reply for external outcoming document. Therefore, we designed External Incoming window to archive information for all employees who get the security permit from the ministry. Their information will be stored in the records see Figure 13.

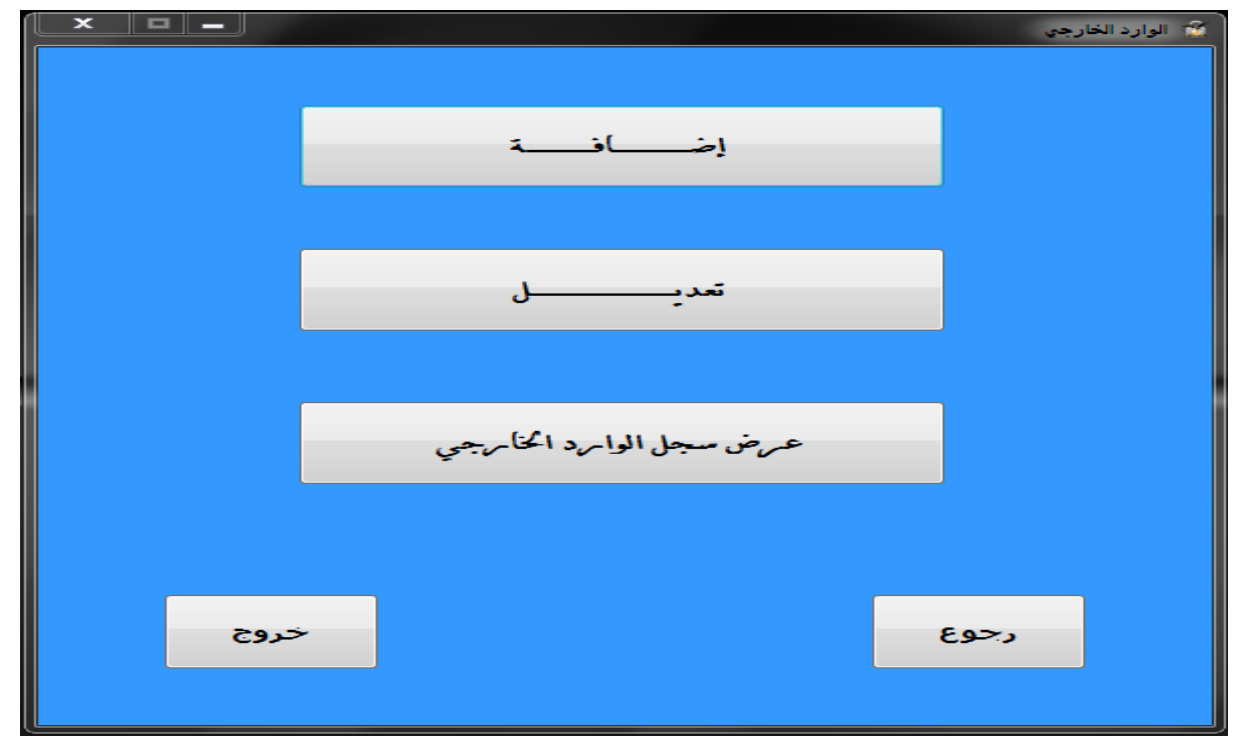

Figure 13: External Incoming

In this window also we have the ability to Add, Edit, and view the information for all Employees who get the security permit.
The last station in our project is the Internal Outcoming document. It issues the final document for employees who asked for security approval and send them report. So, we designed this window see figure 14 . 


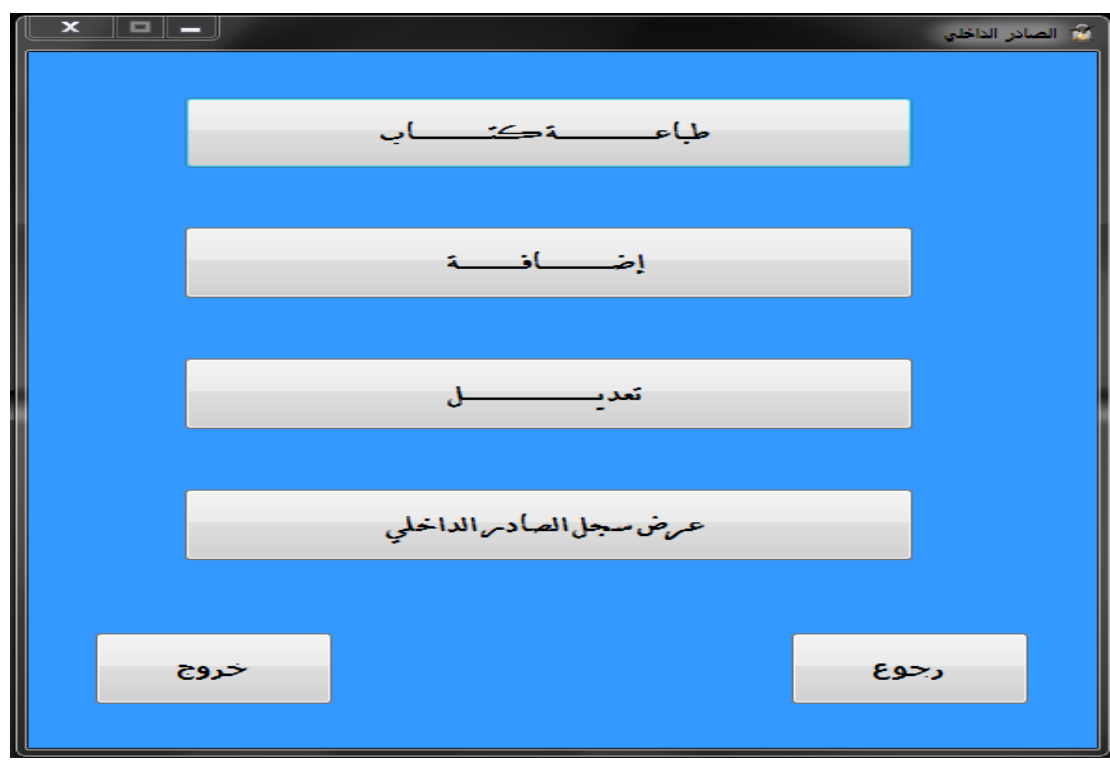

Figure 14: Internal outcoming window

This window has the ability to Add, Edit and view the information to archive all information. Also, we designed the print out-coming internal window to print a document that will be sent as a final report see figure 15 .

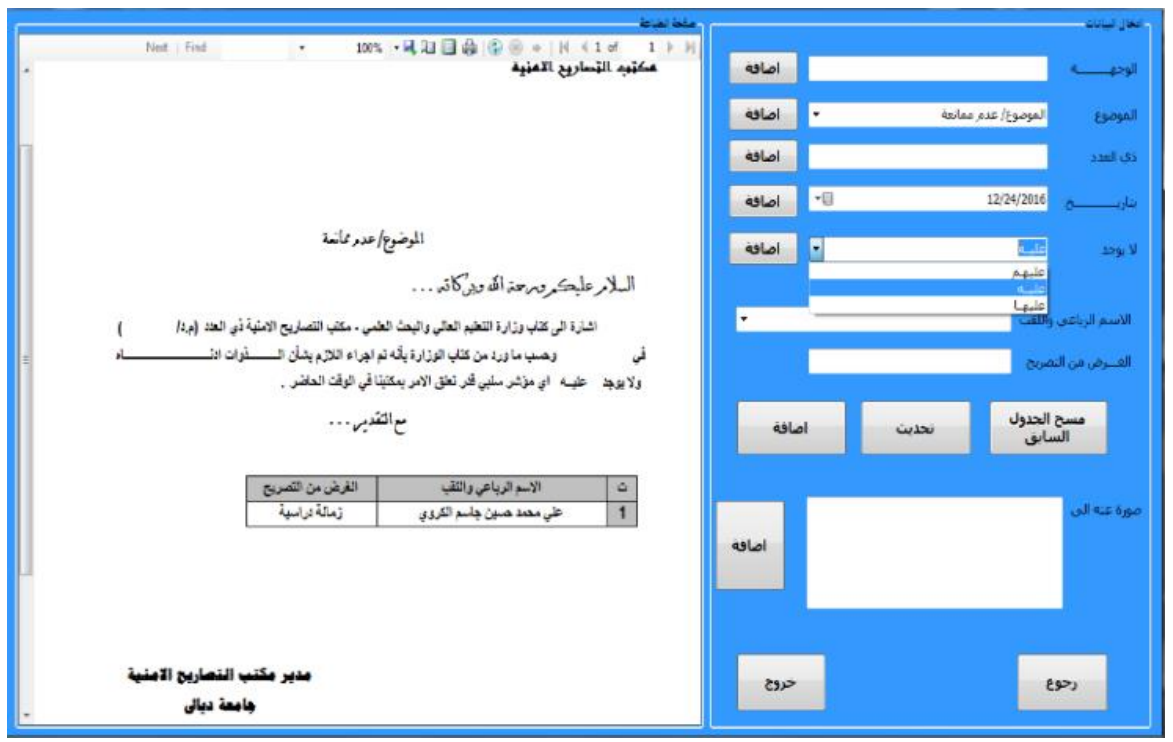

Figure 15: Print the final report

\section{CONCLUSION}

In this project, the authors proposed and implemented a new

working mechanism for Security Permits Office at University of Diyala by designing professional databases management system based on visual $\mathrm{C \#}$ and Microsoft Access. This program showed that visual C\# and Microsoft Access are a powerful, simple, modern, quick, easy, and very user-friendly softwares. Also, they are an efficient pair for such kind of database management system. As a result, our databases management system organizes the work in the Office of Security Permits and makes everything easy to deal with it such as storing data, adding, deleting, and printing reports. Moreover, it is a successful Databases management system and a great tool for storing, arranging a huge amount of data to avoid losing the data. Finally, the Security Permits Office at University of Diyala adopted this database management system in their daily routine work. This project has been nominated as one of the best projects and got a thankful letter from the Ministry of Higher Education and Scientific Research in 2017 as an appreciation for our efforts. 


\section{References}

[1] A. Bhatia and V. Bansal, Databases Management System, Alpha science 2014.

[2] Toby J. Teorey., Database Modeling \& Design: The Fundamental Principles (Morgan Kaufmann Series in Data Management Systems): Morgan Kaufmann Pub,1994.

[3] H. M. Salih, H. N. Al-Anbagi, and M. S. Mohammed, "Design and Implementation of Investigative Committee System," Diyala Journal of Engineering Sciences, vol. 13, no. 1, pp. 84-91, Jan. 2020.

[4] Nita Hewitt R., Audrey Rutkosky R., and Ian R., Microsoft Access2016, EMC/Paradigm,2016.

[5] J. Walkenbach, Microsoft Office 2010, 1st ed. Indianapolis, IN: Wiley Publishing, 2010.

[6] Benjamin Perkins, Beginning C\# 7 Programming with Visual Studio. Wrox; 1 edition, 2018.

[7] M. Halvorson, Microsoft Visual Basic, 1st ed. Redmond, Wash.: Microsoft Press, 2010

[8] John Sharp, Microsoft Visual C\# Step by Step, Microsoft Press; 8 edition, 2015 .

[9] G. Hillar, B. Brinzarea, J. Spohn and R. Steckly, C\# 2008 and 2005 threaded programming beginner's guide, 1st ed. Birmingham, U.K.: Packt Pub., 2009. 